\title{
Bronchiolitis: Can objective criteria predict eligibility for brief hospitalization?
}

Lance Brown, MD, MPH; ${ }^{*}$ David G. Reiley, MD; ${ }^{*}$ Aaron Jeng, BS $;^{\dagger}$ Steven M. Green, MD*

\begin{abstract}
Objective: To determine if 3 objective criteria - pulse oximetry, respiratory syncytial virus (RSV) testing, and age - could be used to predict which children hospitalized with bronchiolitis will have brief ( $<36$ hour) hospitalizations and therefore be potential candidates for admission to short-stay observation units.

Methods: This was a retrospective medical record review of medically uncomplicated children 3 to 24 months of age with emergency department and hospital discharge diagnoses consistent with bronchiolitis who were admitted to a general pediatric ward in our university-based, tertiary care hospital between Jan. 1, 1992, and Nov. 12, 2002. Multiple logistic regression was used to assess the predictor variables.

Results: Our study consisted of 225 patients (45\% female) with a median age of 7 months (interquartile range [IQR], 4-11 mo; range, 3-22 mo). Median pulse oximetry value was $94 \%$ (IQR $91 \%-96 \%$; range $76 \%-100 \%$ ), and $71 \%$ of the patients tested positive for RSV. Thirty children (13\%) had brief hospitalizations $<36$ hours, and the median hospital length of stay for the entire study group was 70 hours (IQR 46-108 h; range 6-428 h). None of the 3 predictor variables were independently associated with brief hospitalization.

Conclusions: Pulse oximetry, RSV testing and age do not predict which children will have brief hospitalizations and are appropriate candidates for admission to short-stay observation units.
\end{abstract}

Key words: pulse oximetry, respiratory syncytial virus, observation unit

RÉSUMÉ

Objectif : Déterminer si trois critères objectifs, soit l'oxymétrie de pouls, l'épreuve de dépistage du virus respiratoire syncytial (VRS) et l'âge, pourraient servir à prédire quels enfants hospitalisés pour une bronchiolite auraient une courte durée de séjour ( $<36$ heures) et seraient par conséquent des candidats potentiels à l'admission dans des unités d'observation de courte durée.

Méthodes : Il s'agit d'une revue rétrospective des dossiers médicaux d'enfants âgés entre 3 et 24 mois sans complications médicales dont le diagnostic de congé du département d'urgence et de I'hôpital était une bronchiolite et qui furent hospitalisés au département de pédiatrie générale de notre hôpital universitaire de soins tertiaires entre le 1er janvier 1992 et le 12 novembre 2002. L'analyse par régression linéaire fut utilisée pour évaluer les variables prédictives.

Résultats : Notre étude incluait 255 patients (45\% de sexe féminin) dont l'âge moyen était de 7 mois (écart interquantile [EIQ], 4-11 mois; éventail 3-22 mois). La valeur moyenne de l'oxymétrie de pouls était de $94 \%$ (EIQ $91 \%-96 \%$; éventail $76 \%-100 \%$ ), et chez $71 \%$ des patients, le résul-

From *Loma Linda University Medical Center and Children's Hospital, Loma Linda, Calif., and +Loma Linda University School of Allied Health Sciences, Loma Linda, Calif.

Received: Jan. 6, 2003; final submission: Apr. 2, 2003; accepted: Apr. 28, 2003

This article has been peer reviewed.

Can J Emerg Med 2003;5(4):239-44 
tat de l'épreuve de dépistage du VRS était positif. Trente enfants (13\%) furent hospitalisés brièvement ( $<36$ heures) et la durée de séjour moyenne pour l'ensemble du groupe à l'étude fut de 70 heures (EIQ 46-108 heures; éventail 6-428 heures). Aucune des trois valeurs prédictives prise isolément n'était associée à une courte durée de séjour.

Conclusions : L'oxymétrie de pouls, l'épreuve de dépistage du VRS et l'âge ne permettent pas de prédire quels enfants auront une courte durée hospitalisation et seront des candidats appropriés à l'admission dans des unités d'observation de courte durée.

\section{Introduction}

Every year, bronchiolitis-related hospitalizations cost the Canadian health care system approximately $\$ 23$ million (1993 dollars) and the American system US\$300 million (1998 dollars)..$^{1,2}$ US data show that between 1980 and 1996 the number of hospitalizations for bronchiolitis increased 2.4-fold. ${ }^{3}$ The reasons for this increase are unknown, but may include increased utilization of child care centres (with related exposure to respiratory viruses), a greater number of medically complicated children surviving early infancy, and a change in admitting practices based on the introduction of pulse oximetry to clinical practice in the early $1990 \mathrm{~s}^{3-5}$ In addition to the rising admission rate, there is substantial variability in admission practices across sites. ${ }^{6,7}$

Most children hospitalized with bronchiolitis are previously healthy, born at term, and have relatively brief hospitalizations in which concurrent serious bacterial infections and clinical deterioration are rare.$^{8,10-12}$ Consequently, many children admitted with bronchiolitis may be candidates for short-stay observation units. ${ }^{13,14}$ If objective criteria available in the emergency department (ED) can identify children appropriate for brief admission to short-stay units, ${ }^{6,7}$ a significant reduction in hospital lengths of stay and substantial cost savings are possible. ${ }^{15}$

Previous studies have suggested that higher pulse oximetry values, ${ }^{8,16,17}$ negative results of respiratory syncytial virus (RSV) testing,,$^{16,17}$ and older age ${ }^{8,17}$ are predictive of shorter hospitalizations. Our objective was to determine whether these 3 objective criteria can be used to predict which children admitted with bronchiolitis have brief hospitalizations and are potential candidates for admission to short-stay observation units.

\section{Methods}

\section{Design and subjects}

We retrospectively reviewed the charts of patients admitted with a diagnosis of bronchiolitis at a tertiary care university hospital between Jan. 1, 1992, and Nov. 12, 2002.
Children aged 3 to 24 months were eligible for inclusion if they were hospitalized through the ED with an ED diagnosis compatible with bronchiolitis and had a hospital discharge diagnosis of bronchiolitis based on the International Classification of Diseases, 9th rev (ICD-9) code 466.1. Because ED diagnoses were not recorded in ICD9 format, we identified the following list of compatible ED diagnoses: RSV pneumonia, viral pneumonia, firsttime wheezing, wheezing with hypoxia, and difficulty breathing. Children were excluded if their medical record could not be located, if they had an underlying medical condition or concurrent diagnosis that would have prolonged the hospital stay, if they required intensive care unit (ICU) admission, or if the key predictor variables (room air pulse oximetry and RSV testing) were not performed.

\section{Standard care}

During the study period, to facilitate isolation of RSVpositive children, it was hospital policy to perform RSV tests on all children admitted with a diagnosis of bronchiolitis. RSV testing was performed using one of 2 tests: Directigen RSV (Becton, Dickinson and Co., Sparks, Md.) or IMAGEN RSV (DAKO, Ltd., Cambridgeshire, UK). Otherwise, our institution had no specific care protocols for the management of bronchiolitis, and treatment was at the discretion of the attending physicians.

\section{Data collection}

All patients 3 to 24 months of age with a discharge diagnosis of bronchiolitis were identified in the hospital database. Trained abstractors reviewed the charts, identified eligible children and recorded key data elements, including initial pulse oximetry reading, RSV test result, gender, and the exact dates of birth, admission and discharge. Given the objective nature of these data, we did not blind the abstractors to the study objective. All data were transcribed onto standardized study forms, and the process was monitored by the principal author (L.B.). For eligible children, the ED triage time and hospital discharge order time were used to calculate the duration of hospitalization to the nearest hour. 
For excluded children, duration of hospitalization was calculated to the nearest day. A priori, we defined "brief hospitalizaton" as hospitalization for less than 36 hours, and considered children with brief admissions to be potential candidates for treatment in a short-stay unit.

\section{Reliability testing}

A second data abstractor, blinded to the results of the first review, independently abstracted a convenience sample of $12 \%$ of the charts. We assessed interobserver reliability for the data collection process by determining the concordance rate and unweighted kappa statistic.

\section{Data analysis}

We performed a multiple logistic regression analysis to assess the association between pulse oximetry value, RSV test result and age (predictor variables) with brief hospitalization (dependent variable). We determined that there were a sufficient number of brief hospitalizations to support these 3 predictor variables in accordance with standard recommendations. ${ }^{18}$ In addition, we performed a similar logistic regression analysis to assess the association between pulse oximetry value and age with brief hospitalization in the subset of children who were RSV positive. Predictor variables retaining an association with brief hospitalization $(p<0.05)$ were considered to have an independent association. We then calculated the area under the receiver operating characteristic (ROC) curve and performed goodness-of-fit analysis using the Hosmer-Lemeshow test. Bootstrap validation was used to obtain $95 \%$ bias-corrected confidence intervals (CIs) for each predictor variable. Because much of the data was non-normally distributed we reported descriptive data using medians and interquartile ranges (IQRs). Our Institutional Review Board approved this study.

\section{Results}

During the 10-year study period, 697 children aged 3 to 24 months had a discharge diagnosis of bronchiolitis. Of these, 472 were excluded for the reasons specified in Figure 1 and Table 1 . The study group $(n=225)$ was $45 \%$ female, $71 \%$ RSV positive, and had a median age of 7 months (IQR, 4-11 mo). Median pulse oximetry value was 94\% (IQR, 91\%-96\%), and median duration of hospitalization was 2.9 days (IQR, 1.9-4.5 d). Excluded patients were slightly older (median age $8 \mathrm{mo}$; IQR, 5-14 mo) and had a longer duration of hospitalization (median $4 \mathrm{~d}$; IQR, 2-7 d). The interobserver agreement for our data abstraction was excellent: ${ }^{19}$ concordance rates for pulse oximetry,

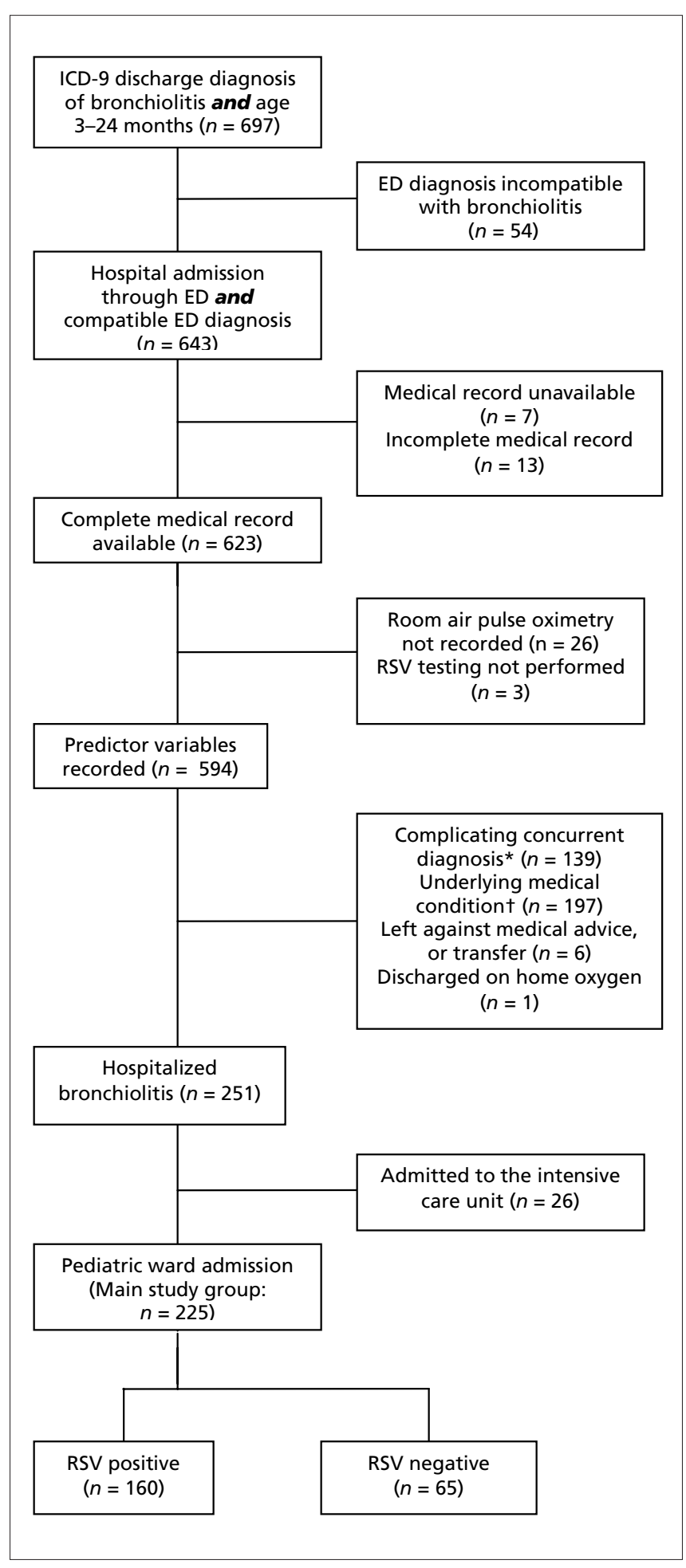

Fig. 1. Study flowsheet. * Complicating concurrent diagnoses included apnea, dehydration, status asthmaticus, facial cellulitis, sepsis, smoke inhalation, pneumococcal pneumonia, Gram negative sepsis, varicella, gastroenteritis, diarrhea, urinary tract infection, esophageal reflux and feeding problems. †See Table 1 for list of underlying medical conditions. ICD-9 = International Classification of Diseases, 9th rev; ED = emergency department; RSV = respiratory syncytial virus 
RSV and age were $88 \%, 100 \%$ and $96 \%$, with corresponding kappas of $0.87,1.0$ and 0.96 .

In the study group, 30 children (13\%) had brief hospitalizations of $<36$ hours. Multiple logistic regression revealed that none of the 3 predictor variables were independently associated with brief hospitalization (Table 2). Of the 160 children who were RSV positive, 23 (14\%) had brief hospitalizations. In this subset, neither pulse oximetry nor age were predictive of brief hospitalization (Table 3 ).

\section{Discussion}

Previous studies suggest that lower oxygen saturation, ${ }^{8,16,17,20,21}$ RSV test positivity ${ }^{16,17}$ and younger age $e^{8,16,21,22}$ are associated with more severe illness and longer duration of hospitalization in children with bronchiolitis. While this may be true, we found that these objective criteria could not be used to identify a patient group who would require only brief $(<36 \mathrm{~h})$ hospitalization.

Previous studies show that children under 3 months of age $^{8}$ and those with complicating comorbid conditions (e.g., bronchopulmonary dysplasia, congenital heart disease) have longer hospitalizations for bronchiolitis..$^{10,21-23}$

Table 1. Underlying medical conditions in 197 patients that caused them to be excluded from the study

\begin{tabular}{ll} 
Medical condition & $\begin{array}{c}\text { No. (and \%)* } \\
\text { of patients }\end{array}$ \\
\hline $\begin{array}{l}\text { Bronchopulmonary dysplasia or } \\
\text { congenital lung disease }\end{array}$ & $69(35)$ \\
$\begin{array}{l}\text { Congenital heart disease } \\
\text { Technology-dependent / medically } \\
\quad \text { complicated children }\end{array}$ & $63(32)$ \\
Taking corticosteroids at time of admission & $29(15)$ \\
Tracheomalacia or other known upper & $20(10)$ \\
$\quad$ airway disorder & $9(5)$ \\
Transplant recipient & $4(2)$ \\
HIV/AIDS & $2(1)$ \\
Cystic fibrosis & $1(0.5)$ \\
\hline *Percentages may not add up to 100\% due to rounding & \\
\hline
\end{tabular}

Table 2. Predictors of brief hospitalization in eligible children with bronchiolitis $(n=225)$

\begin{tabular}{lccc} 
Variable & $\begin{array}{c}\text { Odds } \\
\text { ratio* }\end{array}$ & $\begin{array}{c}\text { Bias-corrected } \\
95 \% \mathrm{Cl}\end{array}$ & p value \\
\hline RSV positive & 1.35 & $0.60-3.58$ & 0.52 \\
Age, mo & 1.07 & $0.99-1.15$ & 0.09 \\
Pulse oximetry, \% & 1.05 & $0.95-1.23$ & 0.35 \\
\hline
\end{tabular}

RSV = respiratory syncytial virus; $\mathrm{Cl}=$ confidence interval

* Refers to odds ratio per month of increasing age and odds ratio per $1 \%$ increase in room air oxygen saturation level. The area under the model receiver operator curve was 0.589 . The model demonstrated satisfactory goodness-of-fit (Hosmer-Lemeshow $p=0.763$ ).
Our tertiary centre treats many such children who are not candidates for brief admission. They are not typical of cases seen in community settings and they are not generally candidates for short-stay observation units so, rather than have them skew our study data, we chose to exclude them. Other studies, unfortunately, have not clearly distinguished or excluded children with significant co-morbid illnesses, making comparison with our study difficult. ${ }^{16,17}$ Our data from 225 uncomplicated children hospitalized over a 10 -year period incorporates year-to-year variability in disease severity, making it more generalizable than data from a single-year study.

\section{Pulse oximetry}

All of our study subjects had room air pulse oximetry readings, and we treated oxygen saturation as a continuous variable. Prior authors have applied arbitrary saturation thresholds and treated pulse oximetry as a dichotomous variable. For example, Green and colleagues studied 87 previously well children with RSV infection ${ }^{8}$ and concluded that children with saturation levels $\geq 90 \%$ had shorter hospitalizations than those with levels $<90 \%$ ( $3.2 \mathrm{~d}$ vs. $5.3 \mathrm{~d}$ ). Unfortunately, pulse oximetry was performed on only 67 patients, and 10 of these patients received oxygen prior to the oximetry reading. To complicate matters, the 10 children who had oxygen administered prior to pulse oximetry were included in the hypoxic group, assuming their saturations were low prior to receiving oxygen.

Shaw and coworkers studied 213 infants under 13 months of age with bronchiolitis and correlated resting pulse oximetry values with disease severity. ${ }^{16}$ In this study, infants who were alert, active, well hydrated and able to take oral fluids throughout their illness were defined as having "mild disease," and all other infants were considered to have "severe disease." The authors reported that oximetry values below 2 thresholds (97\% and 95\%) were more likely to have severe disease (relative risk $=$ 3.28-6.31). Unfortunately, the nature of the outcome vari-

\begin{tabular}{|c|c|c|c|}
\hline Variable & $\begin{array}{l}\text { Odds } \\
\text { ratio* }\end{array}$ & $\begin{array}{c}\text { Bias-corrected } \\
95 \% \mathrm{Cl}\end{array}$ & $p$ value \\
\hline Age, mo & 1.06 & $0.96-1.16$ & 0.14 \\
\hline Pulse oximetry, \% & 1.09 & $0.93-1.23$ & 0.18 \\
\hline
\end{tabular}

$\mathrm{RSV}=$ respiratory syncytial virus; $\mathrm{Cl}=$ confidence interval

* Refers to odds ratio per month of increasing age and odds ratio per $1 \%$

increase in room air oxygen saturation level. The area under the model

receiver operator curve was 0.5552 . The model demonstrated satisfactory goodness-of-fit (Hosmer-Lemeshow $p=0.513$ ). 
able and the relatively high pulse oximetry thresholds make this study difficult to compare to ours.

Mulholland and colleagues reported experience using pulse oximetry to assess the severity of illness in a convenience sample of 60 infants with bronchiolitis. ${ }^{17}$ In this study, an arbitrary pulse oximetry threshold of $90 \%$ was used. Illness severity was determined by the maximum fraction of inspired oxygen $\left(\mathrm{FiO}_{2}\right)$ administered during hospitalization. The authors reported that infants with pulse oximetry values $<90 \%$ were more likely to receive $\mathrm{FiO}_{2}$ $\geq 40 \%$ during hospitalization and therefore had more severe disease. However, the pulse oximetry values and $\mathrm{FiO}_{2}$ were not independent in this study. The clinicians used the pulse oximetry values to select the $\mathrm{FiO}_{2}$ delivered. This study design makes comparisons with other studies problematic.

\section{RSV testing}

Some studies, including this one, based the diagnosis of bronchiolitis on clinical findings; other studies required a positive RSV test. . $8,10,11,20-23$ In previous studies using clinical diagnosis, only $42 \%-68 \%$ of patients tested positive for $\mathrm{RSV} ;, 7,16,17,24$ the proportion in the current study was slightly higher, at $71 \%$. The reasons for this difference are unclear, but the distinction may be unimportant, since, in our study population, relevant outcomes in the entire study group did not differ from those in the RSV-positive subset.

\section{Duration of hospitalization}

Although hospitalization rates have risen since the introduction of pulse oximetry, the mean duration of hospitalization for medically uncomplicated children with bronchiolitis has remained steady, at $<3$ days, since the late 1980s ${ }^{8,9}$ In 1989, Green and colleagues ${ }^{8}$ reported a mean duration of hospitalization of 2.5 days for children $>3$ months of age, and in 2001, Kini and colleagues ${ }^{9}$ reported a similar duration of 2.8 days for children $<1$ year of age. The recently published Milliman and Robertson guidelines $^{25}$ recommend a 1-day goal length of stay (LOS) for children hospitalized with bronchiolitis; however, we found that most children stayed longer than 1 day, and our findings are concordant with others who suggest that 1-day LOS does not reflect clinical practice even for uncomplicated cases. ${ }^{2,9}$

In calculating hospital LOS, we used the ED triage time as the starting point. This is an accepted practice, and ED triage time is more well defined and reliable than the time of admission decision, the time an admitting resident is called, the time a bed is assigned, or the time the patient is transferred to the ward. This means, however, that a prolonged stay in the ED would add several hours to the cal- culated hospital LOS, and this should be considered when comparing our data to others. Our primary outcome variable of brief admission adjusts for this to some extent by using $<36$ hours rather than the more common 24 hours applied to short-stay unit admission.

\section{Limitations}

Because this was a retrospective study, we were unable to study potentially confounding variables that may have influenced hospital LOS, such as degree of dehydration. Our main study variables, however, were objective and well documented in the medical record.

This study was conducted in a teaching institution, where discharge orders may be written at the housestaff's convenience or based on teaching rounds or conferences. This may not reflect common practice in non-teaching hospitals.

\section{Conclusion}

Pulse oximetry, RSV testing and age may be independent variables that influence hospital LOS, but they do not identify a subset of children who have brief hospitalizations and are candidates for admission to a short-stay observation unit.

Competing interests: None declared.

Acknowledgments: We thank Tania Shaw and Debbie Washke for their efforts with data collection.

\section{References}

1. Langley JM, Wang EE, Law BJ, Stephens D, Boucher FD, Dobson $\mathrm{S}$, et al. Economic evaluation of respiratory syncytial virus infection in Canadian children: a Pediatric Investigators Collaborative Network on Infections in Canada (PICNIC) study. J Pediatr 1997;131:113-7.

2. Howard TS, Hoffman LH, Stang PE, Simoes EAF. Respiratory syncytial virus pneumonia in the hospital setting: length of stay, charges, and mortality. J Pediatr 2000;137:227-32.

3. Shay DK, Holman RC, Newman RD, Liu LL, Stout JW, Anderson LJ. Bronchiolitis-associated hospitalizations among US children, 1980-1996. JAMA 1999;282:1440-6.

4. Mallory MD, Shay DK, Garrett J, Bordley WC. Bronchiolitis management preferences and the influence of pulse oximetry and respiratory rate on the decision to admit. Pediatrics [Internet] 2003;111:e45-51. Available: www.pediatrics.org/cgi/content /full/111/1/e45 (accessed 2003 May 8).

5. Brown L, Dannenberg B. Pulse oximetry in discharge decisionmaking: a survey of emergency physicians. Can J Emerg Med 2002;4(6):388-93.

6. Johnson DW, Adair C, Brant R, Holmwood J, Mitchell I. Differences in admission rates of children with bronchiolitis by pediatric and general emergency departments. Pediatrics [Internet] 2002;110:e49. Available: www.pediatrics.org/cgi/content/full /110/4/e49 (accessed 2003 May 8).

7. Willson DF, Horn SD, Hendley O, Smout R, Gassaway J. Effect 
of practice variation on resource utilization in infants hospitalized for viral lower respiratory illnesses. Pediatrics 2001;108:851-5.

8. Green M, Brayer AF, Schenkman KA, Wald ER. Duration of hospitalizatiton in previously well infants with respiratory syncytial virus infection. Pediatr Infect Dis J 1989;8:601-5.

9. Kini NM, Robbins JM, Kirschbaum MS, Frisbee SJ, Kotagal UR. Inpatient care for uncomplicated bronchiolitis: comparison with Milliman and Robertson guidelines. Arch Pediatr Adolesc Med 2001;155(12):1323-7.

10. Boyce TG, Mellen BG, Mitchel EF, Wright PF, Griffin MR. Rates of hospitalization for respiratory syncytial virus infection among children in Medicaid. J Pediatr 2000;137:865-70.

11. Brooks AM, McBride JT, McConnochie KM, Aviram M, Long C, Hall CB. Predicting deterioration in previously healthy infants hospitalized with respiratory syncytial virus infection. Pediatrics 1999; 104:463-7.

12. Purcell K, Fergie J. Concurrent serious bacterial infections in 2396 infants and children hospitalized with respiratory syncytial virus lower respiratory tract infections. Arch Pediatr Adolesc Med 2002;156:322-4.

13. Browne GJ. A short stay or 23-hour ward in a general and academic children's hospital: Are they effective? Pediatr Emerg Care 2000;16:223-9.

14. Mace SE. Pediatric observation medicine. Emerg Med Clin North Am 2001;19:239-54.

15. Perlstein PH, Kotagal UR, Bolling C, Steele R, Schoettker PJ, Atherton HD, et al. Evaluation of an evidence-based guideline for bronchiolitis. Pediatrics 1999;104:1334-41.

16. Shaw KN, Bell LM, Sherman NH. Outpatient assessment of infants with bronchiolitis. Am J Dis Child 1991;145:151-5.

17. Mulholland EK, Olinsky A, Shann FA. Clinical findings and severity of acute bronchiolitis. Lancet 1990;335:1259-61.
18. Harrell FE, Lee KL, Matchar DB, Reichert TA. Regression models for prognostic prediction: advantages, problems, and suggested solutions. Cancer Treat Rep 1985;69:1071-7.

19. Fleiss JL. Measuring nominal scale agreement among many raters. Psychol Bull 1971;76:378-82.

20. Wang EE, Law BJ, Stephens D. Pediatric Investigators Collaborative Network on Infections in Canada (PICNIC) prospective study of risk factors and outcomes in patients hospitalized with respiratory syncytial viral lower respiratory tract infection. J Pediatr 1995; 126:212-9.

21. Kneyber MCJ, Moons KGM, de Groot R, Moll HA. Prediction of duration of hospitalization in respiratory syncytial virus infection. Pediatr Pulmonol 2002;33:453-7.

22. McMillan JA, Tristram DA, Weiner LB, Higgins AP, Sandstrom C, Brandon R. Prediction of the duration of hospitalization in patients with respiratory syncytial virus infection: use of clinical parameters. Pediatrics 1988;81:22-6.

23. Moler FW, Ohmit SE. Severity of illness models for respiratory syncytial virus-associated hospitalization. Am J Respir Crit Care Med 1999;159:1234-40.

24. Schuh S, Coates AL, Binnie R, Allin T, Goia C, Corey M, et al. Efficacy of oral dexamethasone in outpatients with acute bronchiolitis. J Pediatr 2002;140:27-32.

25. Schibanoff JM, editor. Pediatric health status improvement and management. Seattle (WA): Milliman \& Robertson Inc; 1999.

Correspondence to: Dr. Lance Brown, Department of Emergency Medicine, A-108 Loma Linda University Medical Center and Children's Hospital, 11234 Anderson St., Loma Linda CA 92354; 909 558-4344, fax 909 558-0121, LBROWNMD@AOL.com 